\title{
ROSA, João Guimarães. Corpo de baile. Edição comemorativa. Rio de Janeiro: Nova Fronteira, 2006.
}

\author{
Claudia Campos Soares
}

Universidade Federal de Minas Gerais

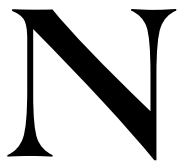

o ano em que se comemora o cinqüentenário de Corpo de Baile, de João Guimarães Rosa, a Editora Nova Fronteira traz a público uma edição comemorativa que não poderia ser mais oportuna.

Trata-se de um trabalho editorial muito bem feito, no qual são reproduzidas muitas e importantes características da primeira edição do livro (1956) - como a divisão das sete novelas que o compõem em dois volumes. Eles vêm envolvidos por um estojo caprichado, que traz ainda um libreto - "Sobre a obra" - contendo: um texto de apresentação dos editores; reprodução fac-similar de três cartas de Guimarães Rosa a Alberto da Costa e Silva, que discutem a publicação de Corpo de baile em Portugal; um pequeno artigo do destinatário comentando a correspondência; e uma apreciação crítica de Paulo Rónai que, apesar de publicada no mesmo ano em que o conjunto de novelas de Rosa, ainda hoje oferece importantes chaves de leitura para a obra.

Talvez, entretanto, a principal contribuição que esta edição poderá trazer à compreensão crítica da obra rosiana seja a reunião das sete novelas nos mesmos dois volumes da primeira edição - sem subtítulos individualizadores e distribuídas na seqüência que para elas pensou inicialmente o seu autor.

Foi de grande acerto a opção por este formato, pois ele dá, novamente, visibilidade a uma característica estrutural do livro: a coesão profunda que subjaz à sua diversidade aparente. Como se sabe, as novelas de Corpo de baile não apresentam unidade de ação e, por isto, podem ser lidas independentemente umas das outras. Entretanto, há um sentido de conjunto a elas subjacente, fato que a segunda edição da obra tratou de 
acentuar: em 1960, Corpo de baile saiu publicado em volume único.

A partir da terceira edição, entretanto, o livro foi subdividido em três, sub-intitulados Manuelzão e Miguilim (1964), No Urubuquaquá, no Pinhém (1965) e Noites do sertão (1965). Alberto da Costa e Silva - que já intermediara a relação entre João Guimarães Rosa e o editor português António de Souza Pinto para a publicação de Sagarana em Lisboa - dá mais informações sobre o assunto:

A edição lisboeta de Sagarana, de 1961, foi muitíssimo bem recebida. E Souza-Pinto dispôs-se a publicar, sem mais demora, Corpo de baile, embora tivesse receio de que uma obra em dois grossos volumes, que sairia necessariamente cara, de um escritor ainda pouco conhecido em Portugal, não fosse de venda fácil.

A essa altura, a camaradagem que se estabelecera entre mim e Rosa no Itamaraty já se havia voltado em amizade. Escrevi-lhe sobre o novo projeto de Souza Pinto. E, no retorno de uma das malas diplomáticas, chegou-me a carta de Rosa, na qual propunha, por motivos práticos, que se dividisse Corpo de baile em três volumes independentes, tendo o primeiro o título de Miguilim e Manuelzão. Pedia-me que consultasse o Souza-Pinto sobre a idéia.

Souza-Pinto exultou: estava solucionado o seu problema. ${ }^{1}$

A carta de Rosa a que Alberto da Costa e Silva se refere é muito importante porque esclarece as circunstâncias da divisão de Corpo de baile em 3 volumes. Nela, Rosa afirma ser o livro (àquela altura publicado em um único volume), "grossudo demais, e os tipos muito miúdos são hostis à vista e à alma da gente". ${ }^{2}$

Os comentários de Rosa a Costa e Silva, contudo, também demonstram que o autor, mesmo se rendendo à necessidade editorial de dividir o livro para facilitar-lhe a difusão, ${ }^{3}$ teria tomado certos cuidados para que

${ }^{1}$ ROSA, 2006 ("Sobre a obra"), p.16-17.

${ }^{2}$ ROSA, 2006 ("Sobre a obra"), p.11.

${ }^{3}$ A afirmação de que Rosa se "rendeu" a esta forma de publicação deve-se ao fato de o escritor haver recusado, antes, a José Olímpio, a publicação de qualquer das novelas do livro isoladamente, conforme nos informa o texto de apresentação dos editores à edição comemorativa de Corpo de baile: "Depois de toda a repercussão que João Guimarães Rosa teve em 1946 com a publicação de Sagarana, o editor José Olympio, preocupado com a construção do novo autor, recomendoulhe que publicasse pelo menos uma das estórias de seu próximo livro separadamente, para que ele não ficasse muito tempo afastado da cena literária. Guimarães Rosa não aceitou o conselho (...) porque havia uma organicidade na 
não se perdesse, com a mudança, o caráter unitário que presidiu sua composição:

Na minha carta de volta, não escondi a Rosa que sempre vira os poemas de Corpo de baile como unidos uns aos outros pelas epígrafes de Plotino e Ruysbroeck o Admirável ${ }^{4}$ e que sofria em ver a obra desmembrada. Em resposta, Rosa consolou-me, ao precisar que pretendia manter Corpo de baile como uma espécie de cabeçalho ou título geral para os três livros, que seriam publicados e vendidos separadamente. ${ }^{5}$
Embora Rosa se preocupasse em adotar medidas editoriais que mantivessem, apesar da divisão em três volumes, o sentido de conjunto que unificava a obra, nas edições que têm sido publicadas desde então este sentido foi ficando cada vez mais esquecido. A partir da terceira, as partes de Corpo de baile foram sendo publicadas de forma cada vez mais autônoma, o que fez com que quase se perdesse a noção de que foram concebidos como partes de uma só obra. ${ }^{6}$

obra que preparava que não havia como apresentá-la desmembrada" (ROSA, 2006 - "Sobre a obra" -, p.5). Por isto, só dez anos depois de Sagarana, Corpo de baile seria publicado - em sua forma integral.

${ }^{4}$ Um outro elemento unificador de Corpo de baile são as oito epígrafes que o apresentam ao leitor. Tratam-se de quatro trechos extraídos das Enéadas, do neoplatônico Plotino; três trechos de O anel ou a pedra brilhante, de Ruysbroeck, místico brabanção do século XIV. Há ainda uma oitava epígrafe (que Costa e Silva não menciona): a letra do "Coco de festa, do Chico Barbós", composição de forte sabor regional que Rosa afirma em carta a Edoardo Bizzarri, tradutor do livro para o italiano, ter recolhido na fonte, ao ouvi-lo tocado, cantado e dançado em suas andanças pelo interior de Minas Gerais (BIZZARRI, p.24). A partir da terceira edição elas foram distribuídas entre os três volumes.

${ }^{5}$ ROSA, 2006 ("Sobre a obra"), p.17.

${ }^{6} \mathrm{Na}$ edição de 2001 (que era a mais recente de Manuelzão e Miguilim, No Urubuquaquá, no Pinhém e Noites do sertão até este ano) a única indicação de que os volumes integram um projeto maior é o discreto Corpo de baile que aparece, entre parêntesis e em tipos menores, logo abaixo do nome atribuído a cada volume. Os subtítulos tardiamente acrescentados ascendem a títulos também na ficha bibliográfica impressa nas costas da página de rosto, na qual a indicação do nome do conjunto de estórias desaparece completamente. Somente na orelha dos livros os editores informam o leitor acerca da concepção geral da obra. 
A idéia de unidade, entretanto, fundamenta a arquitetura do livro. Ela está por trás, por exemplo, do número de novelas de que se compõe Corpo de baile. elas são sete, o número dos conjuntos perfeitos - são sete os dias da criação, os planetas da cosmologia tradicional, os ramos da árvore cósmica... A idéia de unidade também está fortemente presente no título que congrega as novelas: tratase de um corpo, um organismo, um sistema resultante do inter-relacionamento entre suas partes constitutivas.

Uma das conexões entre as novelas de Corpo de baile mais imediatamente reconhecíveis é a sua realidade físico-social. A esmagadora maioria das narrativas rosianas está situada espacialmente no que poderia ser chamado, em sentido amplo, de sertão. Mas o sertão tem suas nuances. Uma delas se apresenta em Grande sertão: veredas; outra, em Corpo de baile-os dois livros publicados, com meses de diferença, em 1956. Tratam-se de duas partes de uma mesma realidade histórico-social, como se discute a seguir.

A ação em Corpo de baile se passa mais exatamente nos "campos gerais", espaço econômico-social contíguo e complementar em relação ao sertão propriamente dito. De uma forma geral, e em vários sentidos, pode-se dizer, com as palavras do ex-jagunço Riobaldo, que os gerais "correm em volta" do sertão. São, portanto, uma espécie de ante-sala dele.

Ambos se identificam com o meio histórico-social onde se desenvolveu a pecuária extensiva no Brasil. São também ambos espaços longínquos, onde as instituições sociais que garantem os direitos civis estão distantes da maioria das pessoas. Por isto, a ambos se costuma relacionar o sentido de interior agreste, ainda não desbravado, desconhecido, não urbano, distante do "desenvolvimento" do sul e/ou do litoral. Riobaldo diz que no sertão, "criminoso vive seu cristo-jesus arredado de arrocho de autoridade"; e seo Deográcias, personagem de "Campo geral", primeira novela de Corpo de baile, diz em certo momento da narrativa que estava escrevendo uma carta ao Presidente da República para pedir providências contra os "criminosos brutos" que apareciam nas redondezas ameaçando os moradores da região. ${ }^{8}$

Não há muitas leis e criminosos vagam por toda parte, mas há uma diferença de grau entre o sertão e os gerais. O sertão-mais profundo na geografia e no arcaísmo de seus usos e costumes - é lugar onde bandos de

\footnotetext{
${ }^{7}$ ROSA, 1976, p. 9.

${ }^{8}$ ROSA, 2004, p. 482.
} 
jagunços têm livre trânsito e percorrem latifúndios e terras devolutas prestando serviços aos grandes proprietários e se envolvendo em grandes batalhas, como as que são narradas em Grande sertão: veredas. Já os gerais são principalmente espaços onde, como afirma Deise Dantas Lima, "o proprietário tem sua riqueza defendida e reproduzida não pela ação espetacular dos jagunços, mas pela labuta rotineira dos lavradores da terra alheia e dos vaqueiros".?

Nas fazendas de gado dos gerais se organizam pequenas comunidades rurais compostas por: proprietário e/ ou seu capataz, vaqueiros, pequenos lavradores e agregados de feitios vários. ${ }^{10}$ Estas novelas tratam da vida familiar em muitas de suas dimensões e possibilidades. ${ }^{11}$ Já no sertão de Grande sertão: veredas os homens são jagunços, e peregrinam sozinhos, marginais, desgarrados da vida familiar.
Por tudo isto, percebe-se que nos gerais se está um pouco menos longe da cidade, das instituições que organizam a vida social. Aí, por exemplo, existem pessoas - ainda que poucas - que sabem escrever, tem consciência de seus direitos civis e reivindicam-nos como seo Deográcias - mesmo que de forma desarticulada, solitária e, portanto, ineficaz.

A linha que separa sertão e gerais, entretanto, é tênue; a distinção é sutil; e os ambientes muitas vezes se confundem. Nem para os seus moradores os limites entre eles são inquestionáveis. É o que demonstram as palavras de Riobaldo em Grande sertão: veredas:

\begin{abstract}
“(...) isto é o sertão. Uns querem que não seja: que situado sertão é por os campos gerais a fora a dentro, eles dizem, fim de rumo, terras altas, demais do Urucúia. Toleima. Para os de Corinto e do Curvelo, então, o aqui não é dito sertão?"
\end{abstract}

\footnotetext{
${ }^{9}$ LIMA, 2001, p.16.

${ }^{10}$ Administradas pelo próprio dono temos, em Corpo de baile, a fazenda de Cara-de-Bronze (na novela homônima), a de seo Senclér (em "A estória de Lélio e Lina") e a de iô Liodoro (em "Buriti"), por exemplo; administradas por capatazes são a fazenda do Mutum, onde moram Miguilim e sua família (em "Campo geral"); e a fazenda da Samarra, cujo administrador é Manuelzão, protagonista de "Uma estória de amor".

${ }^{11}$ Ou da dúvida quanto a formar uma, caso do protagonista de "O recado do morro", o guia-enxadeiro Pedro Orósio. Não por acaso, trata-se esta da única novela de Corpo de baile que não se passa em uma fazenda, mas no trânsito entre várias delas e uma cidadezinha do sertão.
} 
E conclui: "Enfim, cada um o que quer aprova, o senhor sabe: pão ou pães, é questão de opiniães". A imprecisão acaba desmanchando o realismo do mapa porque, como se sabe, o sertão (e os gerais) éo mundo e está (estão) em toda parte. ${ }^{12}$

O fato de habitarem um mesmo espaço - geográfico e histórico, ainda que amplo e de limites imprecisos permite aos personagens de determinadas estórias reaparecerem em outras, outra característica que dá unidade a Corpo de baile. Não se encontrando muito afastados no espaço, eles se movimentam pelas novelas como em um universo único, podendo, eventualmente, aparecer, desaparecer e reaparecer estórias adiante.

O caso mais notório é o de Miguilim/Miguel. Em "Campo geral" e "Buriti", respectivamente a primeira e a última novela do livro, um mesmo personagem é mostrado em dois momentos - descontínuos - de sua trajetória existencial. Na primeira, encontramos Miguilim - um menino que tem entre 7 e 8 anos de idade e que, ao final da estória, deixa a família e vai para a cidade com um "doutor" que passava, na ocasião, pela região. Reencontramos mais tarde este mesmo personagem, já adulto, em "Buriti", retornando à fazenda do Buriti Bom para pedir em casamento a filha do fazendeiro iô Liodoro.

Mas há muitos outros casos. Os irmãos de Miguilim - Tomé, Drelina e Chica - também reaparecem mais velhos em "A estória de Lélio e Lina". Tomé ainda é mencionado pelos vaqueiros da fazenda de Cara-deBronze, na novela homônima e o misterioso fazendeiro é igualmente mencionado em "A estória de Lélio e Lina". O Grivo, o amigo de Miguilim, que em "Campo geral" o encantava com suas "histórias compridas, diferentes de todas", é o vaqueiro que vai buscar "o quem das coisas" para o fazendeiro do Urubuquaquá. ${ }^{13}$ Miguilim guarda entre suas lembranças dos tempos do Pau-Roxo, o lugar onde sua família morara antes de se

${ }^{12}$ ROSA, 1976, p.9. Mesmo nos gerais, há gradações no que se refere ao nível de afastamento das novelas em relação aos centros urbanos do litoral e/ou do sul - ou seja, em relação a Brasil onde chegou a modernização -, mas esta não é uma discussão adequada aos limites desta resenha. Aqui só interessa ressaltar a diferença - que se sabe imprecisa, principalmente em certas situações limítrofes - entre sertão e gerais. Alguns aspectos desta questão foram mais detalhadamente discutidos em SOARES, 2002.

${ }^{13}$ ROSA, 1994, p.510 e 691, respectivamente. 
mudar para o Mutum, forte impressão relacionada à "fazenda grande dos Barbóz". ${ }^{14}$ Mais duas vezes este sobrenome, com ligeiras variações, é citado em Corpo de baile: Chico Braabóz é o violeiro que encon-tramos na festa de Manuelzão, em "Uma estória de amor"; e Chico Barbós'é também o autor do "coco de festa" de que já se falou aqui.

Pelo que já foi discutido até aqui, é possivel perceber que as novelas de Corpo de Baile mantêm estreitas relações entre si. Apesar de serem, em certo sentido, autônomas, elas estão profundamente interligadas. O conjunto de narrativas é capaz de sustentar, simultaneamente, a autonomia das estórias individuais e a unidade do conjunto.

Os sentidos desta unidade, entretanto, estão longe de ser elucidados pela crítica - que até agora tem se atido, na maioria dos casos, ao estudo das novelas individuais. $\mathrm{Na}$ verdade, isto não é pouco, uma vez que se tratam de narrativas extremamente densas e complexas, cada uma a sua maneira. Talvez estudar em detalhes as novelas individualmente, ou em pequenos grupos, seja um primeiro passo necessário, pois permitirá que se tornem visíveis mais conexões entre elas.

Heloísa Vilhena de Araújo é uma das poucas críticas da obra rosiana que tem se atido ao estudo de Corpo de baile como um todo. ${ }^{15}$ Ela lê o livro à luz das epígrafes de Plotino e Ruysbroeck que o apresentam ao leitor. A estudiosa observa que tais epígrafes indicam a linha de leitura que o autor tinha em mente ao escrever o livro. Em carta a Bizzarri, Rosa a chamou de "metafísico-religiosa" e a ela atribuiu a mais alta cotação entre os elementos que entrariam na composição de sua obra. ${ }^{16}$

Seguindo por esta trilha interpretativa, Heloísa Vilhena de Araújo identificou uma correspondência entre as novelas de Corpo de baile e os sete planetas da cosmologia tradicional

\footnotetext{
${ }^{14}$ ROSA, 1994, p.467. Em carta a Edoardo Bizzarri, Rosa justifica as pequenas variações no nome do personagem da seguinte forma: "o barroco mistifório (= mixórdia) de nomes do Chico, denotando nossa absoluta incapacidade em embarcar num só aspecto a personalidade de uma pessoa interessante" (BIZZARI, 1981, p. 81-82).

15 ARAÚJO 1992 e 1996.

${ }^{16}$ Nesta ocasião, Guimarães Rosa atribuiu um ponto a "cenário e realidade sertaneja"; dois a "enredo"; três pontos a "poesia"; e quatro a "valor metafísicoreligioso” (BIZZARRI, 1980, p. 58).
} 
- o que faria do livro uma figuração do céu e dos corpos celestes; vale dizer, um modelo mítico-místico de ascese. De acordo, portanto, com a visão da pesquisadora, o conjunto de novelas pode ser visto como uma representação simbólica do caminho para o paraíso e funda-se em uma concepção de viagem da alma.

A leitura de Heloísa Vilhena de Araújo, entretanto, não se detém na análise minuciosa e exaustiva das possibilidades interpretativas de muitos dos próprios caminhos que aponta. ${ }^{17} \mathrm{E}$ deixa alguns outros, igualmente importantes, de fora. É o que se percebe no fato de a estudiosa excluir de sua investigação - fundamentada, justamente, nas epígrafes do livro - uma delas, o coco de festa do Chico Barbós.
A estudiosa, como se vê, opta por enfocar a obra sob o viés universalista que é, certamente, um seu componente importantíssimo; sua leitura deixa de fora, entretanto, por exemplo, a dimensão particular e local de Corpo de baile. O procedimento adotado na edição comemorativa de recolocar todas as epígrafes juntas e nas posições originalmente pensadas para elas pelo autor ajudará a dar visibilidade também ao fato de que, para se compreender este livro, é tão importante a atenção à tradição erudita do ocidente quanto às palavras de um cantador popular do sertão. É do encontro entre estas duas "tradições" que nasce o peculiaríssimo terceiro discurso que Rosa nos apresenta em Corpo de baile.

${ }_{17}$ Este é um dos motivos pelos quais os estudos de Heloísa Vilhena de Araújo devem ser lidos. Eles acabam deixando indicados muitos caminhos por onde prosseguir a investigação. 


\section{Bibliografia}

ARAÚJO, Heloisa Vilhena de. A raiz da alma. São Paulo: EDUSP, 1992.

ARAÚJO, Heloisa Vilhena de. A pedra brilhante. In: O roteiro de Deus: dois estudos sobre Guimarães Rosa. São Paulo: Mandarim, 1996.

BIZZARRI, Edoardo. João Guimarães Rosa: correspondência (com seu tradutor italiano). 2. ed. São Paulo: T. A. Queiróz, Instituto Cultural ÍtaloBrasileiro, 1980.

LIMA, Deise D. Encenações do Brasil rural em Guimarães Rosa. Niterói: EdUFF, 2001.

ROSA, João Guimarães. Ficção completa. v. 1. Rio de Janeiro: Nova Aguilar, 1994. . Grande sertão: veredas. Rio de Janeiro: José Olímpio, 1976.

SOARES, Claudia Campos. Movimento e ordem nos gerais rosianos: a família e a formação do herói em "Campo geral". 187p. Tese (Doutorado) - Faculdade de Filosofia, Letras e Ciências Humanas, Universidade de São Paulo, São Paulo, 2002. 